\title{
Review on Compound Animal Feed Processing in Ethiopia: Condition, Challenges and Opportunities
}

\section{Keywords: Compound feed; Ethiopia; Animal feed}

\begin{abstract}
Feed both in terms of quantity and quality is a major bottleneck for livestock production in Ethiopia. The use of feed from commercial sources is, however, very limited due to shortage of feed supply and inefficient marketing system. Feed prices are increasing from time to time and mainly exacerbated by the increasing trend in export market of agro-industrial by-products and double taxation in mixed rations. The supply of agro-industrial by-products that constitute more than half of the ingredients used in mixed rations has not been growing commensurate with the growth in demand. As a result, the price of ingredients and manufactured feeds has been increasing at a very fast rate.
\end{abstract}

The problems facing the compound feed industry are multifaceted and thus require commensurate solution by the different actors. Provision of incentives, speeding up enforcement of feed legislation, accreditation of laboratories to increase chemical analysis, awards and recognition for consistent compliance to quality standards, rules and regulations, avoidance of multiple taxation, assure adequate feed supplies and reliable quality of raw materials and finished feeds at affordable prices.

Therefore, assessing the conditions, challenges and opportunities of compound feed manufacturing is of paramount importance for effective and efficient utilization of the resources to enhance the productivity of the livestock sector in the country.

\section{Introduction}

Ethiopia has a large livestock population and diverse agroecological zones suitable for livestock production and for growing diverse types of food and fodder crops. However, livestock production has mostly been subsistence oriented and characterized by very low reproductive and production performance.

Livestock production contributes up to 80 percent of farmers income in Ethiopia and about 20 percent of agricultural GDP. Ethiopia has the largest livestock population of any country in Africa. Nutritional factors are the binding constraint to sustaining livestock production in the country. During the latter part of the dry season, livestock feed is normally in short supply and is also of poor quality.

Despite its contribution to the economy and small holders' livelihood, the production system is not adequately market-oriented and livestock productivity remains very low due to various constraints that include poor nutrition and disease prevalence. These problems are compounded by inefficiencies in the input (feed, genetic material and veterinary services) and output (livestock and livestock products) marketing, including poor market infrastructure, lack of marketing

\section{Journal of}

Nutrition and Health

\author{
Demissie Negash* \\ Ethiopian Meat and Dairy Industry Development Institute, Ethiopia \\ *Address for Correspondence \\ Demissie Negash, Ethiopian Meat and Dairy Industry Development Institute, P. \\ O. Box 1573 Bishoftu, Ethiopia; E-Mail: demisenegash@gmail.com \\ Submission: 21 October, 2017 \\ Accepted: 23 November, 2017 \\ Published: 27 November, 2017 \\ Copyright: $\odot 2017$ Negash D. This is an open access article distributed \\ under the Creative Commons Attribution License, which permits \\ unrestricted use, distribution, and reproduction in any medium, provided \\ the original work is properly cited.
}

support services and limited market information [1]. Among these constraints issues related to feed are the most remarkable ones. Feed shortage in quantity and quality has been a critical problem in Ethiopian livestock production system [2]. The single largest expense in animal production is feed cost and it dictates feasibility of livestock enterprise.

Developing a compound animal feed processing plant in Ethiopia is a promising opportunity. Here we feature an example of a green field opportunity, in which an investment of $\$ 3$ million in a new animal feed plant could establish a processor with an installed capacity of 30,000 metric tons per year and an estimated IRR (Interest Rate Return) of 35-40\% over 10 years. However, information concerning livestock feed demand and supply, feed quality issues, feed marketing, feed prices, price trends are scarce.

Generally, the compound animal feed manufacturing in Ethiopia is not proportional with the animal resources in the countries and the potential in which it is available for the feed industries. Therefore, this paper summarizes the compound animal feed manufacturing and their contribution, challenges and opportunities in Ethiopia.

\section{Background}

In the main, the demand for animal feeds is derived from the demand for animal products as human food, and the general pattern is that this demand rises in response to increases in income and population. However, it is difficult to gauge total demand; it cannot be estimated from published trade figures since many compound feeds and their ingredients are not imported into the developing countries on a large scale because of high transport costs, their bulk being great relative to their value. While there appears to have been a rapid rise in the production of compound feeds in many countries in recent years, it is likely that the potential market is much greater, and that there is considerable room for expansion of the industry.

The greater increase in demand for animal products comes from urban areas where families living above the subsistence level are concentrated; this demand may be sufficient to justify the setting up of integrated animal production and feed compounding enterprises. In general, therefore, demand for compound feed is associated with intensification of livestock production. However, any attempt to 
Citation: Negash D. Review on Compound Animal Feed Processing in Ethiopia: Condition, Challenges and Opportunities. J Nutri Health. 2017;3(2): 5.

increase productivity through the production and use of compound feeds should be made as part of a wider programme including the development or introduction of appropriate breeds of animals with good genetic capacity and of husbandry and management methods. Effective diagnosis and control of infectious diseases is a vital component of livestock production and utilization of livestock products.

Since animal products can deteriorate rapidly, especially at higher temperatures, a further requirement for the expansion of animal production industries is an efficient and hygienic system for slaughtering and the distribution of animal products. This will often involve the expense of refrigerated transport and storage, together with the deployment of skilled management and labour as well as the availability of capital.

From the point of view of the supply of compound feeds, the principal cost to the manufacturer is that of raw materials, which amount to as much as $80 \%$ of operating costs in the models described later in the bulletin. Because of high transport costs the tendency will be to use locally available materials, even in locations with good access to external transport. Although many developing countries are fooddeficit areas, the supply in some countries or areas is moving into surplus largely as a result of the introduction of new high-yielding crop varieties. Some of these countries are now seeking other market outlets for the products, in order, among other things, to avert the fall in price and consequent loss of income to producers likely to be caused by a change in the market situation. Compound feed mills may be linked to a source of raw materials, such as a wheat mill or oilseed crushing plant; to a market outlet, such as a poultry or dairy enterprise; or they may be independent.

Traditionally the feed industry has been linked to the supply of the raw materials, as these were generally the by-products of other processes and of low value relative to the main product. However, certain factors have now caused a movement towards market orientation. In the first place, mainly as a result of advances in nutritional science made by enterprises controlling the raw materials, their value has improved to a very great degree. At the same time nutritional knowledge has become more widespread, so that the demand for byproducts has increased and their prices have risen, thereby reducing the advantages of supply orientation. Secondly, since the distribution system in developing countries is often poor, and since feeds are usually made for particular markets, sales advantages are likely to be gained from market proximity. This will also have the effect of reducing the size of feed mills compared to those in developed countries, which is reflected in the emphasis on small-scale mills in this bulletin.

\section{Why balanced feeds?}

A balanced ration must be nutritionally adequate and be consumed in sufficient amounts to provide for the level of production desired at reasonable cost. The required nutrients must be available in the quantity of dry matter an animal can consume within 24 hours. If not, the ration is not considered to be balanced [3]. Animal production has been taking place over a long time, with the availability of compound feed being only a relatively recent innovation. Most livestock will grow on feeding systems consisting of a small range of components, or even a single component, but production levels may be low and if the nutrient levels in the feed are not balanced, wastage of those present in excess will occur. In general, feeding costs make up $75-80 \%$ of the total costs of livestock production and monitoring and close control of this aspect is essential for profitable projects. Studies on the composition of raw materials and the formulation of feed are aimed at producing a balanced feed. This is a feed which is designed to provide the animals' daily requirement of all known nutrients, and no more, and is intended to obtain maximum levels of production with minimum wastage of nutrients and at minimum feasible cost. For intensively kept poultry or pigs, compound feed may be the only source of feed and must therefore be balanced. In some cases, for example, dairy cattle, compound feed may be a supplement to other feeds such as forages and roughages, and in this case it should be formulated in such a way that the complete ration will be balanced.

The manufacture of compound feed is therefore a service industry, in that the end product contains only those components added in the raw materials, or as supplements and additives. It must be kept in mind therefore that the cost of production and distribution of compound feed must not exceed the increase in value of animal production from balanced feeds compared with that from unbalanced or single component feeds. If it does, then it is not providing a useful service. While it may be difficult to quantify the ' differences in production levels and hence the acceptable cost of compound feed production, consideration of this point emphasizes the importance of taking all possible steps to ensure optimal formulation, adequate quality control, and minimization of equipment and operating costs at all stages.

\section{Role of the animal feed industry}

Despite being an important link in the livestock production chain, the animal feed industry is important to help ensure the safety of food for human consumption, and in order to achieve this producers must adhere to good manufacturing practices in the procurement, handling, storage, processing and distribution of animal feed [4]. Recent outbreaks such as bovine spongiform encephalopathy (BSE), Escherichia coli and Salmonella have highlighted the importance of the animal feed industry in public health, and although some curative measures may simply be improving staff training in feed mills, other measures are more complex and require a strong and active institutional presence [4]. For example, government bodies should be responsible for quality assurance and setting industry standards to be adhered to. Other more complex and long- term duties may involve carrying out research on feed to attain an all-inclusive knowledge base of the nutritional characteristics of available feed ingredients, which also leads to the restriction or limited use of certain ingredients.

Developing the feed industry also presents an opportunity for the crop and livestock sectors to benefit from each other's production activities. Livestock and crop production have often been treated as mutually exclusive activities which compete for the same resources, and national development efforts have failed to integrate the two [15]. However, the two sectors can go hand in hand. For example, feed manufacturers, through the use of crop residues, can add value to some of the major crops used for animal feed production. Furthermore, as a general rule, the animal feed industry cannot compete with the industries which produce food for human consumption, that pay 
Citation: Negash D. Review on Compound Animal Feed Processing in Ethiopia: Condition, Challenges and Opportunities. J Nutri Health. 2017;3(2): 5.

ISSN: $2469-4185$

higher prices for raw materials, and only the remaining industry by-products which have satisfied their requirements, can be used in the animal feed industry [5]. Thus, both crop producers and food manufacturing industries can benefit from the value addition generated from animal feed production.

The feed manufacturing industry also plays an important role in the socio-economic development of the country, making important contributions to employment, income generation, and to linkages within the value chain. Furthermore, an efficient animal feed industry, producing affordable feed of high quality, can help ensure that smallholder livestock keepers are not excluded from the market opportunities presented by the socio-economic transformation taking place in Ethiopia.

\section{Demand for compound feeds}

The markets for the different compound feeds are concentrated along the stated corridor, where the feed processing enterprises and intensive and semi-intensive livestock farms (dairy, cattle fattening, poultry and pig) are found. Feed millers complain that private livestock producers do not use their products for the following reasons: high price per quintal, lack of trust on their product (lack of animal performance), lack of awareness/knowledge about the existence of complete manufactured animal feeds and the majority of livestock producers in the country are subsistence and not market-oriented. They stated that the price rise of compound feeds is associated with the general increase in food prices coupled with lack of tax exemptions on raw materials (AIBP) and double taxation on their products. Consequently, most of the urban and peri-urban livestock producers decided to run their own feed mixing operations and resulted in diminishing of compound feed market. However, they do not make efforts to create their markets through services and technical assistance or advertising [6].

On the other hand, low purchasing power of the smallholder/ subsistence farmers due to lack of market oriented livestock production system resulted in a great impact on the potential market for compound feeds. The total demand for compound animal feed is low. Furthermore, there is low demand for compound feeds during fasting time. As a result, the current low demand for compound feeds have either given incentive for most of the feed processing enterprises to practice vertical integration, i.e., engagement in modern livestock production (fattening, dairy, poultry and/or pig farming), or they are forced to sell their respective products either with minimum profit margin or sell a product having inferior quality at low price [7].

\section{Current Status, Challenges and Constraints of the Feed Manufacturing Industry}

\section{Challenges faced by the feed industry}

The role of the industry should be that of providing high quality livestock feeds which meet the nutrient requirements of livestock in different stages of growth or production, whilst the production of such feeds remains economical, attainable only through the optimal blending of ingredients [8]. However, as it stands, the feed industry in Ethiopia faces several constraints which ought to be addressed.

The lack of infrastructure means that there are few accredited laboratories which carry out chemical analysis of feeds. As a consequence, there is a little reliable data and information which results in animal agriculture being less competitively priced as compared to developed countries [9]. The low confidence in the nutritional information of feed provided by supplier's means that buyers (livestock farmers) are not guaranteed high quality feed. In itself, this suggests that the industry is under-developed, which can in part be explained by its infancy. Furthermore, formal quality control in Ethiopia is uncommon both at the production site and at the selling point, a situation which is exacerbated by the reported presence of counterfeit labeling in the informal sector [10]. This situation creates a lack of trust between the various stakeholders. The agricultural sector in Ethiopia is characterized by a high degree of informality, and it is assumed that the animal feed sector is no different [11].

As for the farmer, optimal feeding requires accurate information on the nutritional value of feeds in order to develop appropriate feeding strategies for different animals at various growth stages [8]. A recent study by El-Sayed on the Egyptian aquaculture feed industry revealed some of problems which characterize animal feed sectors in developing countries, that is: over half of the feed producers do not carry out proximate analysis, $60 \%$ of producers do not receive quality control inspections, and less than half the samples analyzed matched the values recorded on the labels [12]. In addition to this, marketing supply chains are fragmented and underdeveloped. Transport systems are unreliable and inefficient which increases transaction costs and reduces the quality of perishable agricultural production.

\section{Constraints}

The Ethiopian feed industry has gradually started to move forward. However, it is faced with an array of challenges and constraints. The challenges or constraints faced by the industry are as follow: Unavailability/ shortage and high cost of feed ingredients: Feed mills require a high amount of at least the main ingredients in a feed formula and a large variety of micronutrients (vitamins, minerals, additives). The major components of the formula (grain, oil meals, and industrial by-products) are not always available at the right time and at the right place. The unavailability/shortage also directly results in sky rocketing prices of ingredients with the consequence of high compound feed prices. Money feed mills are currently producing much lower quintals than installed capacity.

Shortage and high cost of feed ingredients; wastage of slaughter by-products; high import cost of vitamins, amino acids macro and micro-minerals; multiple taxation at different stages of animal feed processing; high transport costs; insufficient storage capacity: and lack of market information.

In compound animal feed manufacturing low consideration and awareness of high quality feed, poor quality of ingredients, lack of quality control services and/or poor implementation of the Ethiopian feed standards, low market demand and problems related to the formulation of rations are the challenges faced by the Ethiopian feed industry [13].

\section{Feed manufacturers association}

Although literature and information regarding the Ethiopian animal feed industry association (EAFIA) is almost non-existent, a scoping study carried out by ILRI, found that the EAFIA, which 
Citation: Negash D. Review on Compound Animal Feed Processing in Ethiopia: Condition, Challenges and Opportunities. J Nutri Health. 2017;3(2): 5.

ISSN: $2469-4185$

had been previously set up, has been dormant for many years, but recently there has been growing interest in reviving the association. A strong presence of the association is essential in protecting the interests of the animal feed industry within the country, and is also responsible for ensuring the quality and safety of compound feeds, which is achieved by setting clear rules and good manufacturing guidelines which ensure self-regulation and improved government regulation throughout the supply chain $[14,15]$. Furthermore, associations are useful in providing missing or inadequate services, improving bargaining strength with suppliers, and allowing a greater co-ordination of the flow of input supplies [16]. A feed manufacturers association is also required to address the knowledge gaps within the sector, thereby setting the agenda for research and development $(\mathrm{R} \& \mathrm{D})$ in order to enhance competitiveness and capacity to innovate, so as to ensure sustainable and resource efficient livestock production systems [14]. Overall, the association has the duty to play a central role in the decision- making process within the animal feeds industry, acting as a link between all stakeholders in the sector, both public and private [15].

\section{Volume of industrial feed production}

The capacity of feed mills ranges widely from 0.5 to 12.5 tones/ hour. The output of compound feeds has increased during recent years. Most of the industrial feeds are poultry feeds. The standard for a feed mill is 2000 hours of operation annually. The feed mills in Ethiopia are generally operating much lower than this standard. The main reasons why installed capacities are not used efficiently are the low availability of ingredients, inadequate storage capacity, localized distribution of the plants and various technical limitations [13]. There are more than 50 private and unions commercial feed manufacturing industries in Ethiopia. The country's cattle population and the feed manufactured is not proportional. Table 1 shows the amount of feed produced by some companies.

\section{Feed marketing}

A review of past research works indicated that animal feeds and nutrition research largely concentrated on biological aspects both onstation and on-farm. If adoptions of animal nutrition technologies have to be optimized on the on-farm, feed technology development should be accompanied by efficient feed market system. An efficient feed marketing system is rewarding both for marketing agents and livestock producers.

Feed marketing is not a recent phenomenon in Ethiopia as there are experiences in the past, where farmers used to lease in land for in situ grazing [17]. Recent trends show that feed has become a marketable commodity in all parts of the country, where different

Table 1: Amount of mixed feed (quintals) produced by five feed producers.

\begin{tabular}{|c|c|c|c|}
\hline Name of Feed processing plant & \multicolumn{3}{c|}{ Year } \\
\hline Alema koudijs PLC & $2014 / 15$ & $\mathbf{2 0 1 5 / 1 6}$ & $\mathbf{2 0 1 6 / 1 7}$ \\
\hline Akaki feed processig PLC & 27952 & 38952 & 290060 \\
\hline KAliti feed processing PLC & 35200 & 37600 & 42964 \\
\hline Addis Alem Agric. Development PLC & 18000 & 21500 & 20966 \\
\hline Ethio- Feed PLC & 13000 & 13600 & 15629 \\
\hline
\end{tabular}

Source: Ethiopian meat and dairy industry development institute annual report (1tone $=10$ quintal) market actors market both concentrates and roughage feeds. The availability of alternative feeds has increased the commercialization of feed resources and the price of marketed feeds [18].

The feed market types and marketing practices are different depending upon the livestock production system along with the types of feed. In general, the feed markets can be categorized in to three main markets types. These are markets for compound feeds, markets for industrial by-products, and markets for roughages.

\section{Markets for compound feeds}

The markets for the different compound feeds are concentrated along the Addis Ababa-Adama corridor, where the feed processing enterprises and modern livestock farms (lower cases, and cattle fattening) are found. The market is expanding gradually as a result of the increase in the number of different livestock farms. The current markets for compound feeds are characterized by direct sale to individual purchasers, who normally buy small quantities ranging from one to five quintals per purchase, participation in auctions to deliver to modern livestock farms and for relief purpose, and supplying compound feed based on orders, which is commonly practiced by NGOs that promote livestock production. In addition, linking livestock marketing cooperatives/unions from the pastoral areas of Borena Zone and Somal region by NGOs with feed processing companies has shown promising results that needs to be encouraged in the future [19].

\section{Market opportunity}

Animal feed processing presents a near-term and large-scale opportunity, with a significant domestic demand gap and potential for future exports to regional markets. Assuming proper use of feed, the estimated 2015 demand gap for feed was over 120,000 metric tons for poultry meat alone, indicating that in 2015 , there was a greater than $\$ 157$ million opportunity in feed - this is growing rapidly. This is in itself a highly conservative estimate: not only does it only consider poultry meat alone, but it does not consider planned growth. If Ethiopia achieves even 10\% of Livestock Master Plan targets to increase meat production to 1.93 million MT and egg production to 3.9 billion by 2020 , the demand will grow significantly faster than over the past few years.

Furthermore, Ethiopia is well-positioned to serve the $\sim \$ 2.9$ billion animal feed imports market in North and East Africa. Egypt, Morocco, and Algeria alone comprise 79\% of this market, presenting particularly promising target markets. European markets are the main suppliers of meal for animal feed for Morocco and AlgeriaMorocco imports feed from Spain, while Belgium is the main supplier for Algeria. Ethiopia has an existing export relationship with Egypt amounting to a total of $\$ 34.5$ million in 2015 across product types, making it a ripe market for Ethiopia to enter in animal feed as well.

\section{Conclusion}

The performance of the livestock sector in sub-Saharan Africa over most of the last two decades has been far from impressive. The production and consumption gap for the major food commodities has widened across the continent. The major technical constraints are known and a number of solutions have been suggested though rarely implemented. The need for reconfiguring institutional and 
Citation: Negash D. Review on Compound Animal Feed Processing in Ethiopia: Condition, Challenges and Opportunities. J Nutri Health. 2017;3(2): 5.

ISSN: 2469-4185

policy support in the feed sector is not only limited to economic and biological dimensions of attaining self-sufficiency in foods of animal origin.

Currently the feed industries are operating at about $25 \%$ of their capacity due mainly to limited demand for processed compound feeds, which could be due to increased price of factory mixed compound feeds because of value added tax charges. Another reason cited by some livestock producers is that mixed feeds purchased from processing plants do not meet their expectations with respect to nutritional quality and animal performance. The feed industries should strive to win the trust of their customers, the livestock producers, by addressing the poor nutritional quality issues claimed by most livestock producers.

The government should encourage investment in commercial feed processing. This entails providing some incentives for the partners who participate in feed processing industries. The government should also institute sound policies to assure adequate feed supplies and reliable quality of raw materials and finished feeds at prices affordable to livestock and poultry raisers.

\section{References}

1. Azage Tegegne, Hussen K, Kurtu MY, Gebremedhin B (2008) Traditional cow and camel milk production and marketing in agro-pastoral and mixed crop-livestock systems: The case of Mieso district, Oromiya Regional State. Ethiopia, Improving Productivity and Market Success (IPMS) of Ethiopian Farmers, Project working paper 13, ILRI (International Livestock Research Institute), Nairobi, Kenya pp: 58.

2. Adunga Tolera (2009) Livestock feed supply situation in Ethiopia, in Proceedings of the $16^{\text {th }}$ Annual Conference of the Ethiopian Society of Animal Production (ESAP) on Commercialization of Livestock Agriculture, Addis Ababa, Ethiopia, Part I pp: 21-38.

3. Alemu Yami (2017) Livestock ration formulation and feeding guidelines: reference and training manual fot Ethiopia pp: 5 .

4. FAO and WHO (2008) Animal feed impact on food safety. Report of the FAO/ WHO Expert feed resources for small-scale livestock producers. Proceedings of the second PANESA Workshop held in Nairobi, Kenya, November 11-15, 1985. International Development Research Centre (IDRC), Ottawa pp: 23-34.

5. Shipton TA, Hecht T (2005) A reviews of the animal and aquafeed industries in
South Africa. In: A synthesis of the formulated animal and aquafeed industry in sub-Saharan Africa. Moehl J, Halwart M (Eds), Food and Agricultural Organization of the United States. 26.

6. Dejene $M(2014)$ Livestock feed marketing In Ethiopia: Challenges and opportunities for livestock development pp: 7-8.

7. ATA (2016) Opportunity to invest in a compound animal feed processing plant for poultry, beef, and dairy pp: 1-2.

8. Babić Z, Perić T (2011) Optimization of livestock feed blend by use of goa programming 130:218- 223

9. de Jonge L, Jackson F (2013) The feed analysis laboratory: Establishment and quality control. Setting up a feed analysis laboratory, and implementing a quality assurance system compliant with ISO/IEC 17025:2005. Makkar HPS (Eds), Animal production and Health Guidelines No. 15. Rome, FAO.

10. Kurwijila L, Mwingira J, Karimuribo E, Shirima G, Lema B, et al. (2011) Safety of animal source foods in Tanzania a situational analysis. Prepared for the safe food, fair food project. International Livestock Research Institute. Nairobi, Kenya.

11. Skof A, Utz, Robert (2008) The Informal Economy. In: Sustaining and sharing economic growth in Tanzania (Eds), World Bank Publications.

12. El-Sayed A (2014) Value chain analysis of the Egyptian aquaculture feed industry. World Fish, emphasis on feed and feed-related issues. Journal of Agricultural Economics and Development 2: 134-146.

13. Adugna T, Yirdaw W (2012) Livestock Feed Resources in Ethiopia challenges, opportunities and the need for transformation pp: 59-67.

14. FEFAC (2013) Role and importance of financial instruments for the economic viability of the EU livestock chain: the perspective of the EU feed industry 130: 218-223.

15. Louw A, Schoeman J, Geyser M (2013) Pork and broiler industry supply chain study with Lwoga A, Urio N (1987) An inventory of livestock feed resources in Tanzania. In: Animal Meeting. October 8-12, 2007, Rome.

16. Schmidt S, Magigi W, Godfrey B (2014) The organization of urban agriculture: Farmer associations and urbanization in Tanzania. Cities.

17. Gebremedihin B, Hirpo A, Berhe K (2009) An appraisal of fodder marketing in Ethiopia. In: Dessie T (Eds), Commercialization of livestock agriculture. Proceeding of ESAP held in Addis Ababa, Ethiopia pp: 1-20.

18. Tolera A (2009) Livestock feed supply situation in Ethiopia. In: Dessie T (Eds), Commercialization of livestock agriculture. Proceeding of ESAP held in Addis Ababa, Ethiopia. pp. 21-38.

19. Dawit A, Siyoum B, Yirdawnd W (2012) Feed marketing and quality issue pp: 78-79. 